\title{
Microwave Heating: a Time Saving Technology or a Way to Induce Vegetable Oils Oxidation?
}

\author{
Ricardo Malheiro', Susana Casal2, \\ Elsa Ramalhosa ${ }^{1}$ and José Alberto Pereira ${ }^{1}$ \\ ${ }^{1} \mathrm{CIMO} /$ School of Agriculture, Polytechnic Institute of Bragança, \\ Campus de Sta Apolónia, Apartado 1172, 5301-854 Bragança, \\ ${ }^{2}$ REQUIMTE / Serviço de Bromatologia, Faculdade de Farmácia da Universidade do Porto, \\ Rua Aníbal Cunha, 164, 4099-030 Porto, \\ Portugal
}

\section{Introduction}

The use of microwave radiation for food heating was discovered unintentionally in 1945 by Dr. Percy Spencer (Osepchuk, 1984). In the following years several experiments were conducted in order to improve the technology and food application fields, being exclusively used at the industrial level, mostly for drying, baking, and thawing. The popularization of domestic microwave ovens started in the 70's (Osepchuk, 1984) once the improvements allowed price and size reduction. Microwaves are now indispensible equipments in westerns modern kitchens.

Although there is no formal definition of the frequency range for microwave radiation, these electromagnetic waves occur in the $300 \mathrm{MHz}-300 \mathrm{GHz}$ region. Nevertheless, and in accordance with the industrial, scientific and medical (ISM) frequency bands for noncommunication purposes, only $915 \mathrm{MHz}$ and $2.45 \mathrm{GHz}$ are used for food applications, especially the second due to its worldwide availability.

In domestic equipments, these microwaves (high frequency oscillating electric and magnetic fields) are produced inside the oven, when electrons resonate at high frequencies in an electron tube called magnetron. The electric field is created through an inner cathode and an outer anode presenting a large potential difference between both. Permanent magnets, which compose the magnetron, are responsible for the magnetic field. Once heated, the cathode releases the electrons, traveling from the cathode in an outward spiraling path, eventually making their way to the anode. As the electrons go by resonance chambers, energy is released and received as microwaves by the output antenna. The microwaves are applied to the cavity oven, where the food is heated, via waveguides (Mutyala et al., 2010). The microwaves are reflected and distributed by the stirrer fan and then reflected again by the metallic walls of the container, being absorbed by food and lead to its temperature rise (Fig. 1). This capability to absorb microwave energy is governed by food dielectric properties, and involves primarily two mechanisms: dipolar relaxation and ionic conduction. Food water is often the primary component responsible for dielectric heating. Because of its dipolar nature, water molecules tend to re-orientate with the high frequencies 
oscillating fields, producing heat from collisions with the near particles. The second mechanism occurs with the mineral ions present in food that migrate under the influence of the electric field, also generating heat. Once heat is generated within food, particularly in the regions with higher water content, the process is not limited by the rate of heat flow into the food, conditioned by its thermal characteristics, as specific heat, thermal conductivity, density and viscosity, while the uniformity of heat distribution is greatly improved and the whole food is heated at the same rate.

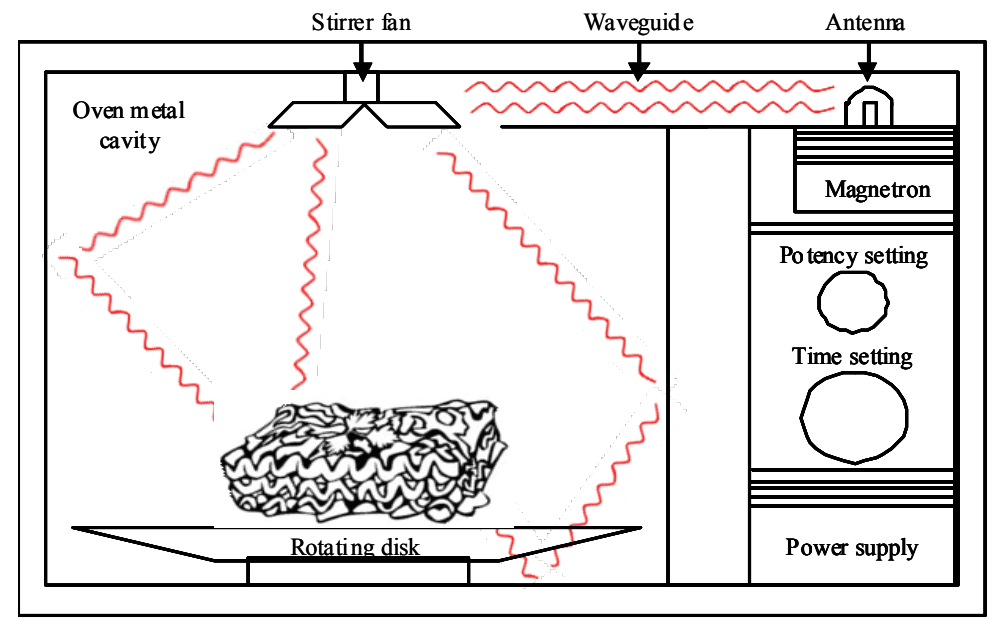

Fig. 1. Simplified scheme of microwave radiation path and absorption by food on a domestic microwave oven.

The heat generate within food is also dependent on the frequencies applied. Lower microwave frequencies (longer wavelengths) allow higher penetration of foods and consequently a more uniform and faster heating (Chavan \& Chavan, 2010). For the occurrence of this mechanism, and to achieve convenient heating, the frequency range of the oscillating field should allow a proper inter-molecule interaction. If the frequency range is too high the inter-molecular forces will stop the movement of the polar molecules before trying to follow the field and to be in phase with it, resulting in an inadequate interaction. By other hand, if the frequency range is too low, polar molecules have sufficient time to align themselves in phase with the field and the interaction with near molecules is not observed.

Altogether, the main reasons for microwave efficiency for food heating, while compared to other conventional cooking methods, are related with the dielectric properties of foods and the microwave frequency, providing inner penetration and faster heat conduction, and the non-dielectric properties of the food containers and equipment, justifying less energy dissemination. Based on these properties, microwave ovens become very useful and convenient mainly at domestic level to defrost, heat and cook food, with reduced times, compatible with the demands of modern society. The food industry saw in this technology a way to follow the modern consumer, and actually this industry contributes largely to the use and dissemination of microwave ovens, once tendency is to create and produce convenient pre-prepared food products that only need to be defrosted, cooked or heated by a microwave oven. 
Microwave food heating, like others technologies, presents also some disadvantages. Depending on the water content and its distribution in the food, different microwave absorption rates are created and the product can be unevenly cooked or with the so called "dead spots" and "hot spots". Some constraints regarding containers must not be disregarded. While metals and aluminum cannot be used, as they will reflect microwaves, only plastic containers specifically designed for this purpose must be used, avoiding migration of potentially dangerous chemicals into food. On the other hand, formation of health hazard compounds during microwave heating and loss of important minor compounds with biological properties is observed, a situation that will be further developed within this chapter, especially regarding food lipids.

\section{Microwave heating effect on food lipids}

The major food components: water, carbohydrates, lipids, protein and minerals interact differently with microwaves. The microwave heating effects on these food constituents, as well as color changes and flavor formation, have been extensively evaluated in several foods. A particularly focus has been devoted to lipids, recognized as being prone to thermooxidative degradation. These lipids include those naturally present in the raw food, but mostly the lipid ingredients added in pre-prepared meals or the lipids used for frying purposes. Microwave frying became popular in recent years, being regarded as an alternative frying technology at the industrial level. While in conventional frying heating is transferred by conduction from the oil to the food, and then by conduction within the food, in microwave frying there is also heat generation directly within the food, due to the dipolar rotation induced in the water (Sahin \& Sumnu, 2009). Among these applications, the main sources of lipids are vegetable oils, justifying their separate study.

Vegetable oils are constituted mainly by triglycerides, with reduced amounts of diglicerides, monoglycerides and free fatty acids. The unsaponifiable constituents, representing less than $10 \%$, encompass important lipossoluble vitamins, as vitamins $\mathrm{E}$ and $\mathrm{A}$, and other minor bioactive components as sterols, chlorophylls, or phenols. The vegetable oil composition will depend mostly on the lipid source (sunflower, soybean, maize, olives, palm, etc) and the technological treatment applied, with the refined seed oils being deprived of several constituents when compared with virgin oils as olive oil.

During microwave heating, as with other heating technologies, different chemical changes could occur that compromises the lipids quality and safety: some components are destroyed while other potentially hazard are formed. The main classical degradation patterns observed in the triacylglycerols include hydrolysis, oxidation, and thermal polymerization. The chemical nature of the fatty acids within the triacylglycerols, particularly their unsaturation degree, will determine its susceptibility towards oxidation and polymerization, while the presence of water will enforce hydrolysis. Other minor components, as vitamins and some sterols, can be regarded as protective factors, against oxidation and polymerization, respectively. The temperature achieved during food heating and the heating period will further determine the extent of the degradation effects, while comparing with other conventional heating technologies.

\subsection{Effect of microwave heating on physical properties of edible oils 2.1.1 Viscosity and density}

In opposition to other common liquids, an increase in viscosity and density values is observed when vegetable oils are heated, as shown by Albi et al. (1997a) for both 
conventional $\left(180^{\circ} \mathrm{C}, 120 \mathrm{~min}\right.$ ) and microwave heating (500W, $\left.120 \mathrm{~min}.\right)$ of olive oil, sunflower oil, and high oleic sunflower oil. However, microwave heating caused a higher increase in both parameters, as depicted in Fig. 2. Yet, when the oils were exposed to microwave energy without any increase of temperature, the results obtained were quite similar to those obtained in the unheated samples, concluding that microwave energy only by itself is not enough to cause viscosity and density increase (Albi et al. 1997a).

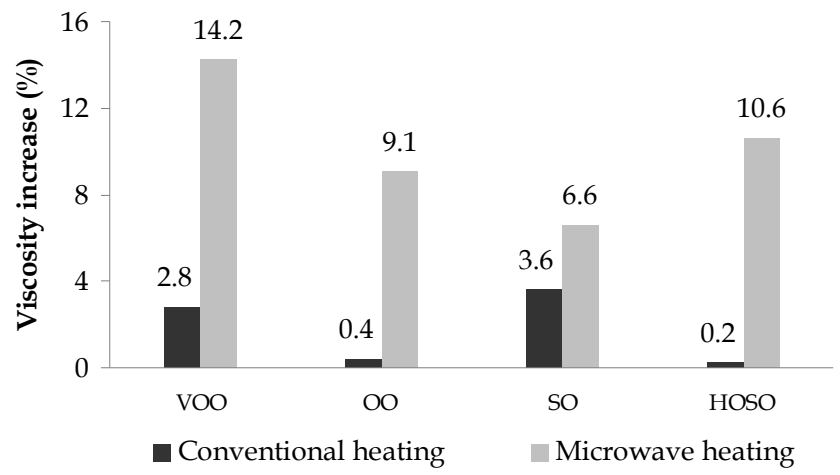

Fig. 2. Viscosity increase (\%) in different vegetable oils subjected to microwave heating and conventional heating (VOO - Extra virgin olive oil; OO - Olive oil; SO - Sunflower oil; HOSO - High oleic sunflower oil). Adapted from Albi et al. (1997a).

Oomah et al. (1998), while studying the influence of microwave heating on grapeseed oil extractability and quality, compared conventional drying $\left(50^{\circ} \mathrm{C}, 2 \mathrm{~h}\right.$, fluid bed dryer) with microwave drying $(950 \mathrm{~W}, 9 \mathrm{~min})$. Both methods provided increased oil viscosity, but a more pronounced effect (2-fold) was observed in the oils extracted from the microwave heated samples.

Viscosity and density increases are temperature-dependent and justified by chemical reactions that take place within the oils. The increased viscosity is related with the formation of cyclic monomers, dimmers and polymers in a non-radical mechanism. The double bonds migration within the unsaturated fatty acids enables the formation of conjugated dienes. These instable structures contribute to the formation of ring structures, allowing bonds between two triacylglycerols, therefore resulting in the formation of larger molecules. The increased proportion of saturated fatty acids, as a result of unsaturated fatty acids oxidation, will further contribute due to their higher melting points (Eskin et al., 1996). The increased density is related with the incorporation of oxygen in the fatty acids (oxidized triglycerides). These parameters will be detailed within the chemical alterations.

\subsubsection{Color}

Color is an important sensorial attribute perceived by the consumer, influencing significantly its acceptance towards vegetable oils, particularly for olive oil. Microwave heating influences the color indexes of seed and olive oils.

When seed oils (soybean, peanut, sunflower and mixture of soybean/peanut oils) were microwave heated from 2 to 18 minutes $\left(120\right.$ to $\left.227^{\circ} \mathrm{C}\right)$ their color changed gradually from yellow-brown to light brown. The color intensity at $420 \mathrm{~nm}$ in the four oils decreased in the following order: soybean oil $>$ mixture of soybean/ peanut oil $(1: 1)>$ peanut oil $>$ sunflower 
oil. The darkening process of seed oils seems to be influenced by the presence of phospholipids, therefore justifying the soybean oil reduced performance regarding this parameter (Hassanein et al., 2003).

Olive oil submitted to microwave heating tends to lose its greenish-golden color becoming paler. In contrast, sunflower oil, as other seed oils, tends to get darker with the yellow light color turning into brown (Fig. 3).
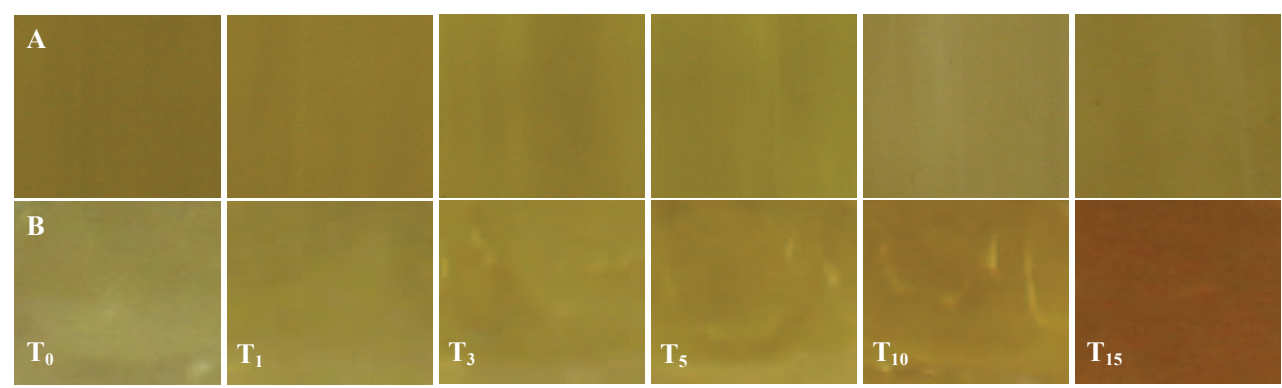

Fig. 3. Effect of microwave heating on color of "Trás-os-Montes" PDO olive oil (line A) and sunflower oil (line $\mathbf{B})$ ( $\mathrm{T}_{0}$ : unheated oils; $\mathrm{T}_{1}: 1$ minute; $\mathrm{T}_{3}: 3$ minutes; $\mathrm{T}_{5}: 5$ minutes; $\mathrm{T}_{10}: 10$ minutes and $\mathrm{T}_{15}: 15$ minutes).

Malheiro et al. (2009) compared three PDO (Protected Designation of Origin) Portuguese olive oils submitted to increasing heating times, from 1 to 15 minutes $(1000 \mathrm{~W})$, simulating general home practices with olive oil containing recipes, and evaluated different color parameters $\left(x, y, \lambda_{\mathrm{d}}, \mathrm{Y} \%\right.$ and $\left.\sigma \%\right)$ as shown in Fig. 4. The parameters $x$ and $y$ are the chromatic coordinates of the superficial point of the chromaticity diagram that corresponds to the light transmitted by the oil. Purity is the percentage of light transmitted by the oil in the prevailing wavelength $\left(\lambda_{d}\right)$, while transparency corresponds to the light transmitted after passing through the oil layer.

Color parameters were quite stable during the first 3 minutes of microwave heating, and began to decrease after 5 minutes, with the exception of transparency $(Y \%)$ where a gradual elevation was observed with the increased exposure time. The reported values and the reduction of green color could be related to the destruction of thermo-labile pigments like chlorophylls and carotenoids, naturally higher in cold-pressed virgin oils than in refined ones, as will be discussed ahead. The reported values are in accordance with eye-naked observations (see Fig. 3).

\subsection{Effect of microwave heating on chemical quality parameters of edible oils \\ 2.2.1 Free acidity}

Triglycerides and diglycerides are prone to thermal hydrolysis, particularly in the presence of water, releasing fatty acids from their ester linkage, and increasing free acidity. This analytical parameter is therefore frequently used to evaluate hydrolysis extension, a very important quality issue. Hydrolysis is influenced by temperature and heat, interface between oil and water, and the existent quantity of water and steam.

Initial oil acidity is also an important parameter that influences oil thermal performance. Free fatty acids are eliminated during refining, providing commercial vegetable oils with low acidity. In opposition, virgin olive oils, being obtained only by physical processes at low 

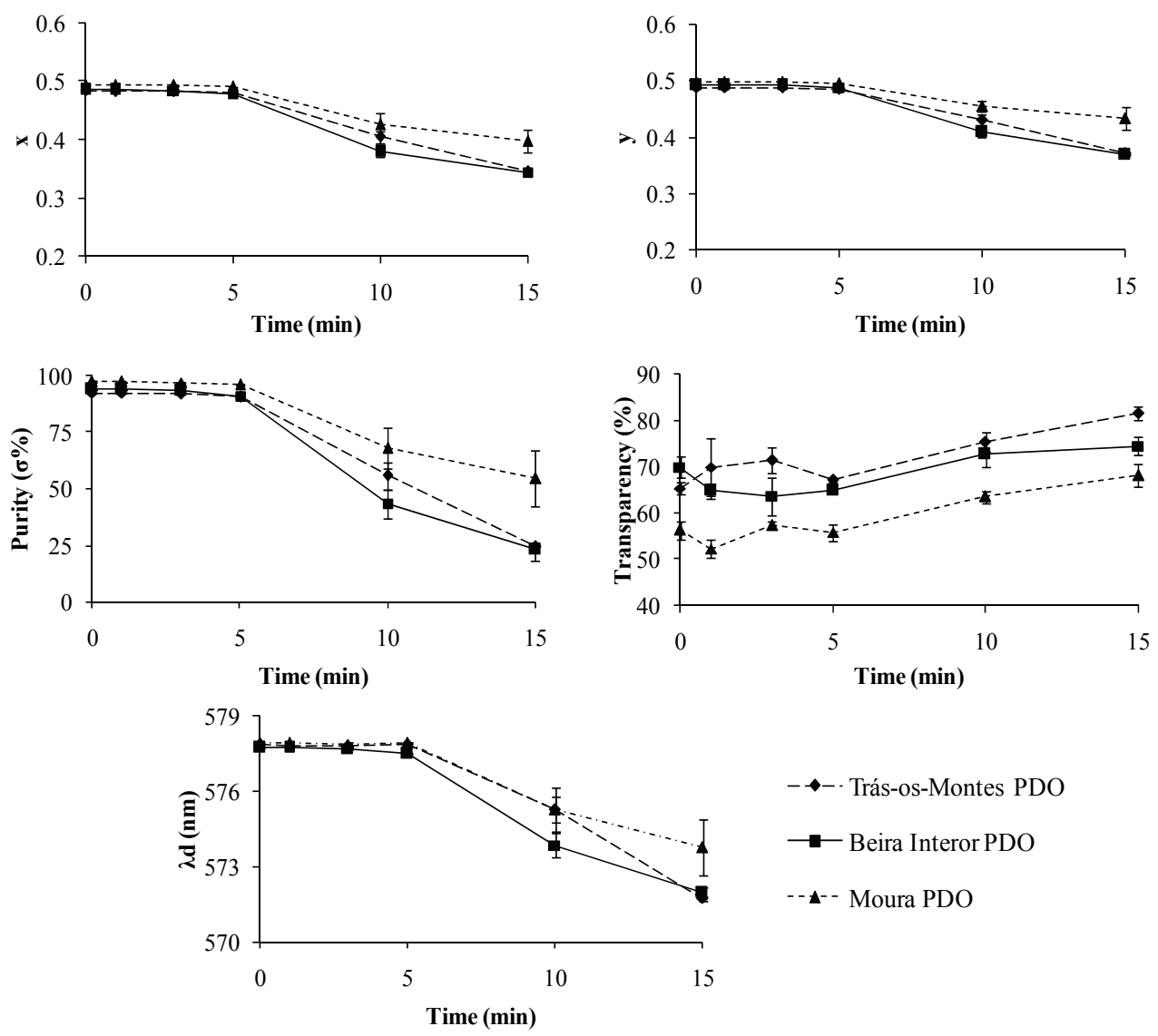

Fig. 4. Color characteristics of three Portuguese PDO olive oils subjected to increasing microwave heating exposure. Adapted from Malheiro et al. (2009).

temperature, could have naturally a higher acidity value, due to the lipases interaction with the triglycerides, and their prices reflect the care given to maintain the acidity as low as possible.

Several author's studied the effect of microwave heating on the free acidity of different vegetable oils: Portuguese virgin and extra virgin PDO olive oils (Malheiro et al., 2009); olive oil (refined + virgin olive oil) (Caponio et al., 2002); Spanish virgin olive oils (Brenes et al., 2002), and Italian extra-virgin olive oils (Cossignani et al., 1998), coconut, palm and safflower oils (Yoshida et al., 1991); peanut, high oleic sunflower and canola oils (Chiavaro et al., 2010); corn and soybean oils (Tan et al., 2001); virgin olive oil, olive oil, sunflower oil, high oleic sunflower oil, and lard (Albi et al., 1997 a,b). All the results provide clear evidence that microwave heating causes a slight increase in the free fatty acids amounts, higher than that obtained by conventional heating. Cerretani et al. (2009) reported a pronounced free acidity increase after 12 minutes of microwave heating $(720 \mathrm{~W})$ of extra virgin olive oil as compared to the other olive oil categories, but this occurred already at extremely high temperatures $\left(\geq 300^{\circ} \mathrm{C}\right)$. 
El-Abassy et al. (2010), using VIS Raman spectroscopy, were capable to compare free acidity increase during microwave and conventional heating in extra virgin olive oil, confirming the results obtained with the classic titration method.

\subsubsection{Peroxide and $\rho$-Anisidine values}

Oxidation is the most common chemical change in vegetable oils, promoted by several factors: oxygen/air, light, heat/temperature, trace metals, among others. It can occur through three distinct reaction pathways: 1 ) nonenzymatic chain autoxidation mediated by free radicals; 2) nonenzymatic and nonradical photooxidation; and 3) enzymatic oxidation. Among these, and under thermal influence, autoxidation via free radicals appears to be the key process in lipid oxidation. During the first oxidative stages hydroperoxydes are formed from unsaturated fatty acids, being the peroxide value (PV) a very sensitive indicator of the extension of primary oxidation of lipids. These unstable peroxides decompose swiftly into secondary oxidation products, particularly aldehydes, alcohols, ketones, acids, dimmers, trimers, polymers and cyclic compounds (Tan et al., 2001), including the volatile compounds responsible for off-flavors in seed oils and olive oils. Therefore, the peroxide value changes along the oxidative process, achieving a maximum due to the initial hydroperoxides formation, and then decreasing when the rate of conversion into secondary oxidation compounds surpasses the former. Therefore, the peroxide value is useful to evaluate the oxidation extent only during the inicial oxidation stages and should be complement with other evaluations. $\rho$-Anisidine value $(\rho-A V)$ is an empirical determination used to assess advanced oxidative rancidity of oils. It is based on the reactiveness of the aldehyde carbonyl bond on de $\rho$-anisidine amine groups, leading to the formation of Schiff base that absorbs at $350 \mathrm{~nm}$. It allows the estimation of secondary products of oxidation of unsaturated fatty acids, principally dienals and 2-alkenals (Labrinea et al., 2001). In opposition to peroxide value, $\rho$-anisidine value increases progressively during the oxidative process, which turns this determination useful to evaluate the oxidative history of the product, namely in abused oils of low peroxide value. The results however, must be interpreted carefully, as the response is more intense with di-unsaturated aldehydes than with mono-unsaturated aldehydes, which in turn are more sensitive than saturated aldehydes. Moreover, $\rho$ anisidine reacts with all aldehydes, irrespective of their origin. This is especially the case for some phenol compounds of virgin olive oil, such as decarboxymethyl oleuropeine dialdehyde, which could interfere in the assessment (Laguerre et al., 2007)

Tan et al. (2001) studied the effect of different microwave potencies on corn and soybean oils. For both the formation of hydroperoxides was higher at low-power setting than in the medium and high power settings. In opposition, the $\rho$-anisidine value increased faster at medium and high-power settings when compared with low-power setting. These results could be related to the temperatures achieved by oils at the different applied settings, indicating an effective increased oxidation at the higher power settings, despite the lower peroxide value. When the two oils are compared, soybean oil reported higher formation of secondary products of oxidation justified by its increased amount of unsaturated fatty acids, particularly linoleic and linolenic acids, both highly susceptible to oxidation. Cerretani et al. (2009) evaluated olive oils during several consecutive heating sessions and also observed that the peroxide value decreased while hydroperoxydes were transformed in secondary products of oxidation, increasing consequently the values of $\rho$-anisidine.

Several reports deal only with the peroxide value. Oomah et al. (1998) reported an increased peroxide value in the oil extracted from grapeseeds dried by microwave when compared 
with air dried ones. Caponio et al. (2003) compared olive oil, sunflower and peanut oils, and reported higher peroxide values for peanut and sunflower when compared with olive oil but the differences between the two heating systems, microwave and conventional, were reduced. While comparing different olive oil categories, Malheiro et al. (2009) observed higher peroxide values on virgin Portuguese PDO olive oils rather than in extra virgin Portuguese PDO olive oils. In this case, virgin olive oils were more vulnerable to oxidation processes than extra virgin olive oils, probably due to their different composition in antioxidant compounds such as phenolics and tocopherols which protects the oils against free radicals and oxidative pathways.

\subsection{3 $\mathrm{K}_{232}$ and $\mathrm{K}_{270}$ extinction coefficients}

UV spectrophotometrical analysis can provide a series of information about oil quality, its conservation status and possible changes occurred during the technological process. Over $90 \%$ of hydroperoxides formed by lipoperoxidation have a conjugated dienic system resulting from stabilization of the radical state by double bond rearrangement. These compounds absorb in the UV range $(235 \mathrm{~nm})$ forming a shoulder on the main absorption peak of nonconjugated double bonds (200-210 nm) (Laguerre et al., 2007). Several secondary oxidation products as well as triene conjugated double bounds absorb in the $270 \mathrm{~nm}$ region, and their presence is usually indicative of extensive oxidation or high thermal stress, as occurring during vegetable oil refining. For olive oil characterization the absorption at 232 $\mathrm{nm}$ and in the $270 \mathrm{~nm}$ region are of special importance, giving information on the oxidative status and enabling to distinguish virgin olive oils categories (EEC, 1991).

These extinction coefficients can provide additional information regarding oil oxidation and are influenced by the effect of microwave heating, as studied by several authors (Albi et al., 1997a; Vieira \& Regitano-d'Arce, 1999; Caponio et al., 2003; Malheiro et al., 2009). Peanut oil and sunflower oil increase rapidly the $\mathrm{K}_{232}, \mathrm{~K}_{270}$ and $\Delta \mathrm{K}$ values, showing that primary and secondary oxidation products are formed in greater extent after microwave heating than under conventional heating, independently of the vegetable oil (Caponio et al., 2003). Peanut oil shows to be more resistant to the formation of oxidation products then sunflower oil (Caponio et al., 2003) reporting lower values after heated for 15 minutes. The results obtained by Albi et al. (1997a) also clearly highlight that conventional heating inflicts lower damage to vegetable oils than microwave heating.

Concerning the microwave heating effect in olive oils, $\Delta \mathrm{K}$ values increase considerably as well the other two parameters, increasing between $40.2-94 \%$ and $276-757 \%$, respectively for $\mathrm{K}_{232}$ and $\mathrm{K}_{270}$ (Malheiro et al., 2009). Virgin PDO olive oil showed higher resistance to the temperature among the olive oils.

The addition of antioxidants to preserve edible oils, although forbidden for virgin olive oils, is a common practice in refined oils. However, no protective effect against microwave induced oxidation was observed in a supplemented corn oil, despite being more noticed when the same oil was heated in a conventional oven (Vieira \& Regitano-d'Arce, 1999).

\subsubsection{Oxidative stability}

Oxidative stability is known as the resistance to oxidation processes established trough well defined conditions. Under normal heating conditions the oxidative oxidation process occurs slowly until a sudden increase in the oxidation rate is observed, the so called induction period, proportional to the unsaturated fatty acids type and amounts, as well as the 
presence of natural or added antioxidants. Accelerated experiments, by using high temperature in the presence of excess bubbling air, are usually performed to calculate and compare the induction period of different lipids.

Albi et al. (1997a) compared microwave and conventional heating (in an electric oven) in several vegetable oils (sunflower, high oleic sunflower and olive oil). A significantly reduced oxidative stability was observed in the microwave heated oils. Among the studied oils, the extra virgin olive oil exhibit better performance against oxidation with both heating methods, mainly due to the its composition, including minor compounds with antioxidant properties (phenolic compounds, carotenoids and tocopherols), lower percentage of linoleic acid (Albi et al., 1997a) and high oleic-linoleic fatty acids ratio. Similarly, the high oleic sunflower oil presented also higher oxidative stability than the sunflower oil.

Chiavaro et al. (2010) evaluated the oxidative resistance of peanut oil, high oleic sunflower oil and canola oil with increasing microwave heating times. Microwave heating during 15 minutes at $(720 \mathrm{~W})$ inflicted an induction time reduction of nearly $26 \%$ and $23 \%$ comparing with initial values, respectively in peanut and canola oils. Concerning high oleic sunflower oil, a higher reduction of the induction time was observed (near $40 \%$ ) but the final oxidative stability was still higher than that present by unheated peanut and canola oils, again a consequence of its chemical composition. Significant negative correlations between exposure time to microwave heating and the loss of oxidative stability were observed for all seed oils $(p<0.05$ to canola oil and $p<0.01$ to peanut and high oleic sunflower oil).

\subsubsection{Polymeric compounds}

Vegetable oils, mainly those rich in unsaturated fatty acids, tend to form larger molecules (polymers) when submitted to extreme conditions of temperature and time. During vegetable oils refining the development of polymers is insignificant but under consecutive frying conditions these compounds are gradually formed. Polymerization mechanism is not completely understood, but it is believed to be due to the formation of either carbon-tocarbon bonds or oxygen bridges between fatty acids, derived from terminating reactions within the oxidation pathway. When an appreciable amount of polymers is produced, an increase in viscosity is observed in the vegetable oils.

Polymeric compounds can be analyzed directly by liquid chromatography (HPSEC). When the polar compounds fraction is previously separated from the triacylglycerides, and then further separated by liquid chromatography, information on polymeric components as well as oxidized triacylglycerols, diglycerols and free fatty acid can be obtained simultaneously. However, the most frequent is to report as total polar compounds that includes all these chemical classes. This parameter is legally established with a maximum value of $25 \%$ for frying oils (Portaria No. 1135/95).

Despite the importance of these hazard compounds from a health point of view, information on total polar compounds and their constituents in microwave heated vegetable oils is scarce. No alterations in the total polar compounds were observed by Albi et al. (1997b) when vegetable oils were submitted to microwaves without being heated. Nevertheless, when microwave and conventional heating procedures were compared, a significantly higher formation of total polar compounds was observed in the microwave heated samples. Concerning to diglycerides and free fatty acids of the untreated and treated samples, no significant differences were observed as expected from the lower free acidity achieved. The amount of thermal induced alterations (polymers and dimmers) and oxidized triacylglicerols was higher in the microwave heated samples. Among the samples analyzed, 
sunflower and high oleic sunflower oils showed higher formation of polar compounds, probably derived from their fatty acid composition.

Dostálová et al. (2005) simulated microwave frying conditions with several vegetable oils heated during 20 minutes, at $500 \mathrm{~W}$, reaching nearly $200^{\circ} \mathrm{C}$. The formation of polymers was observed for all vegetable oils with different rates depending on their fatty acid composition, as usual under conventional frying. Indeed, polymerization is known to arise faster in vegetable oils with higher linoleic acid content. As an adequate safety limit 10 to $12 \%$ of polymeric compounds is usually accepted, although the legal level of total polar compound being $25 \%$. On microwave heating these values were not achieved, even in the samples submitted for 40 minutes. Therefore, if the oil is to be rejected after the microwave treatment, no safety issues are expected. When the oil is intended to be reserved for further use, then a more detailed study is still necessary in order to estimate the number of frying sessions or total heating time allowed, as usual in conventional frying.

\subsection{Effect of microwave heating on chemical composition of edible oils 2.3.1 Fatty acids composition}

Fatty acids are the main constitutes of the saponificable fraction of vegetable oils, being mostly conjugated with glycerol as triacylglycerides. Although, some individual fatty acids are of particular importance for nutritional purposes, they are frequently grouped in classes according with the unsaturation degree of the hydrocarbon chain, as saturated (SFA), monounsaturated (MUFA), and polyunsaturated fatty acids (PUFA). The reaction of oxygen with unsaturated fatty acids is the major cause of deterioration of lipids or lipid-containing foods leading to losses in quality and nutritional value, and to the development of offflavors and hazard compounds.

Several works with vegetable oils investigated the effect of microwave heating in some of these fatty acid fractions, reporting a higher nutritional quality loss with microwave heating when compared to conventional heating (Caponio et al., 2003; Albi et al., 1997a).

Caponio et al. (2003) evaluated three vegetable oils (virgin olive oil, peanut and sunflower oils) by conventional electric oven and microwave heating and reported that while the saturated fraction did not suffer significant changes after heating, both unsaturated and polyunsaturated fractions were significantly decreased. Moreover, microwave heating gave rise to an increased oxidative degradation when compared to conventional electric oven, with significantly lower amounts of both mono- and polyunsaturated fatty acids $(\mathrm{P}<0.05)$ than in conventionally heated oils, higher trans-isomers formation, and higher amounts of non-eluted materials (thermal-oxidized and polymerized materials). When the different oils were compared, the unsaturation degree was reported as influencing the non-eluted material proportion, with the vegetable oils with less polyunsaturated content, like olive oil, being less degraded (Caponio et al., 2003). Nevertheless, the antioxidant compounds present in virgin olive oil could also contribute to a lower formation of thermo-oxidized materials, by reducing the propagation of the oxidative processes. Studying the same oils, plus soybean oil, Hassanein et al. (2003) reported the decrease of oleic and linoleic acid in all samples.

The ratio between linoleic and stearic acids in corn and soybean oils continuously decreased during microwave heating exposure at different power settings (Tan et al., 2001). This is associated to the decrease of unsaturated fatty acids, like linoleic acid, and the increase in the percentage of the sum of saturated fatty acids (Tan et al., 2001) as also reported by Mahmoud et al. (2009). This ratio is often used to evaluate the extent of deterioration caused 
by oxidation once that linoleic acid is susceptible to oxidation whereas palmitic acid is quite stable to oxidation (Tan et al., 2001).

\subsubsection{Sterols composition}

Phytosterols are important component of vegetable oils. They are constant in botanic family and are also influenced by cultivar, oil extraction procedure refining procedures and storage conditions, as well as climatic and agronomic conditions (Cañabate-Díaz et al., 2007). In olive oil, phytosterols are the major constitutes of the unsaponifiable fraction (representing about $20 \%$ ) and $\beta$-sitosterol is the most abundant phytosterol followed by campesterol, stigmasterol, $\Delta^{5}$-avenasterol, $\Delta^{7}$-avenasterol in low amounts. These compounds are very important once possess properties like anti-inflammatory, antibacterial, antifungical, antiulcerogenic and antitumoral activity (Li \& Sinclair, 2002).

The effect of microwave heating in the sterols fraction of vegetable oils is not extensively studied. Albi et al. (1997a) by studying extra virgin olive oil, olive oil, sunflower oil and high oleic sunflower oil did not found significant differences after microwave heating in all the samples. Sterol compounds seem to be resistant to degradation through microwave radiation.

\subsubsection{Tocopherols}

Tocopherols and tocotrienols are natural lipophilic antioxidants, known to inhibit lipid oxidation in fats and oils by modifying the radical chain autoxidation process. These compounds present also an important vitaminic action (vitamin E), being essential from a nutritional point of view.

The effect of microwave heating on tocopherols content of seed oils (Yoshida et al., 1991a,b; Hassanein et al., 2003; Albi et al., 1997b) and different categories of olive oils (Albi et al., 1997b; Brenes, et al., 2002; Malheiro et al., 2009) was studied.

Yoshida et al. (1991) showed that tocopherols gradually decrease with microwave heating time, and that each tocopherol type exhibited different antioxidant activities. In particular, since sunflower oil contains mainly alpha-tocopherol, exhibiting the lowest antioxidant activity, the rate of tocopherol degradation was higher when compared with soybean oil, containing gamma- and delta-tocopherols. These authors also highlight that the free fatty acid amount, present in the unheated oil or formed during the microwave heating process, is an important parameter affecting tocopherols losses (Yoshida et al., 1992).

After microwave heating $\left(18 \mathrm{~min}, 227^{\circ} \mathrm{C}\right)$ of sunflower, soybean, peanut and a mixture of soybean and peanut oils, Hassanein et al. (2003) observed that tocopherol content and exposure time were inversely proportional but still detectable at the end of the process (Hassanein et al., 2003). These results are in accordance to those obtained by Albi et al. (1997b) that reported 72 and $85 \%$ of tocopherols losses after microwave heating (120 min, half-power) of sunflower oil and high oleic sunflower oil, respectively.

With the same exposure time and temperatures, extra virgin olive oil and olive oil (refined olive oil + virgin olive oil) a-tocopherol, the main tocopherol, was completely undetectable (Albi et al., 1997b). Malheiro et al. (2009) also reported the absence of a-tocopherol in Portuguese virgin and extra virgins PDO olive oils after 15 minutes (1000W) of exposure time, while Brenes et al. (2002) reported $60 \%$ to $80 \%$ losses after 10 minutes (500W). This high degradation rate of alpha-tocopherol in olive oil is also frequent in conventional frying mainly because olive oil contains smaller amounts of tocopherols than other vegetable oils, being its natural antioxidant activity attributed to other minor components. 
When microwave heating was compared with conventional heating, higher degradation rates were observed in the former (Albi et al., 1997b, Brenes et al., 2002). Brenes et al. (2002) reported losses after 10 minutes of microwave heating $(500 \mathrm{~W})$ equivalent to those obtained after almost $10 \mathrm{~h}\left(180^{\circ} \mathrm{C}\right)$ under conventional oven heating.

\subsubsection{Phenolic compounds}

Virgin olive oil is a source of at least 30 different phenolic compounds in which oleuropein, tyrosol and hydroxytyrosol are present in higher amounts (Tuck \& Hayball, 2002). Phenolic compounds contributes to the quality of virgin olive oils (Servili \& Montedoro, 2002), and are responsible for a series of important characteristics and properties, such as color, texture and taste (Marsilio et al., 2001), antioxidant capacity (Ben Othman et al., 2009), antimicrobial activity (Sousa et al., 2006) and protection against micotoxins effects (Beekrum et al., 2003). As antioxidants, phenolic compounds contribute to a higher stability against oxidation by protecting the target lipids from oxidation initiators as well as stalling the propagation phase of the oxidative process (Laguerre et al., 2007). Refined oils are deprived of most of the natural phenolics during this technological process.

When exposed to 120 minutes of microwave heating, virgin olive oil and olive oil reported losses around 96 and 85\%, respectively, in their total polyphenols content. Under conventional heating, only a $10 \%$ reduction was observed in the virgin olive oil, compared with a $64 \%$ reduction in olive oil (Albi et al., 1997a). Despite having used long heating periods in both experiments, the results highlight a significant reduction in total polyphenol content. Following these studied, Brenes et al. (2002) submitted virgin olive oils from two Spanish cultivars (Picual and Arbequina) to microwave heating during 5 and 10 minutes $(500 \mathrm{~W})$ in order to simulate domestic conditions and evaluated the individual polyphenols. Under these conditions, the phenolic profile of both oils suffered minor changes due to microwave radiation. Hydroxytyrosol, its oleosidic forms (dialdehydic form of elenoic acid linked to hydroxytyrosol and oleuropein aglycon), and 4-(acetoxyethyl)-1,2dihydroxybenzene suffered a $20-30 \%$ decrease when compared with the unheated samples (Brenes et al., 2002). A slight increase in ligustroside aglycon content and a rising in the formation of oxidized dialdehydic form of elenolic acid linked to tyrosol was observed in the samples heated for 10 minutes. Lignans like 1-acetoxypinoresinol and pinoresinol were not affected by microwave heating, confirming that these compounds are highly stable to microwave heating (Yoshida et al., 1995). The authors concluded that, when compared with frying, microwave heating is a less destructive culinary method regarding the phenol compounds (Brenes et al., 2002).

Pomace olive oil, as other vegetable oils submitted to refining, are naturally deprived or reduced in phenolic compounds, being unusual to report their phenolic content in heating experiments. Olive oil, a blend of refined olive oil with virgin olive oil, also reported lower phenolic compounds compared to extra virgin olive oil. Similarly, extra virgin olive oil, reported higher amounts of individual and total phenolic compounds. Cerretani et al. (2009) compared these olive oil categories under microwave heating and observed around $40 \%$ lost after 6 minutes of microwave, and total depletion after 15 minutes. Under the same heating conditions, a $28 \%$ loss was observed in the extra virgin olive oil at 6 minutes, and $83 \%$ after 15 minutes. The reported losses at 15 minutes are also related to the increasing temperatures observed ( $313{ }^{\circ} \mathrm{C}$ at 15 minutes of heating), contributing to the deterioration of phenolic 
compounds. Concerning the individual phenolic compounds that compose the extra virgin olive oil, lignans like (+)-pinoresinol and 1-acetoxypinoresinol were more stable among all the phenolic compounds detected after 15 minutes of microwave heating. Such results are in accordance with those obtained by Brenes et al. (2002). This is an important result once that these compounds are reported to exhibit beneficial effects on human health (Schouw et al., 2000).

In Fig. 5 the relative losses of some phenolic compounds with microwave heating are reported.

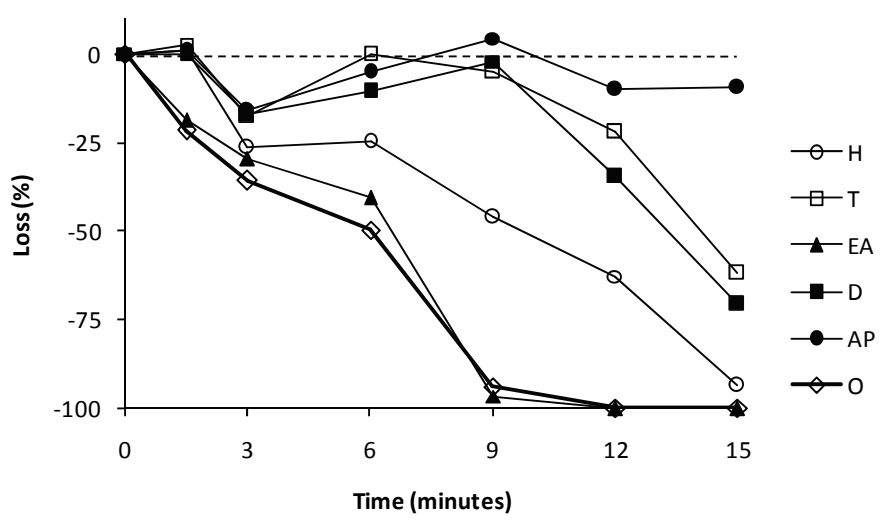

Fig. 5. Effect of microwave heating in some phenolic compounds of extra virgin olive oil. H - Hydroxytyrosol; T - Tyrosol; EA - Elenolic acid; D - Decarboxymethyl-oleuropein aglycon; AP - 1(+)-acetoxypinoresinol; and O - Oleuropein aglycone. Adapted from Cerretani et al. (2009).

At the first heating minutes, until 3 minutes, a constant decrease in the phenolic compounds of the extra virgin olive oil was observed, followed by abrupt losses mainly in hydroxytyrosol, oleuropein and elenolic acid. Amongst the phenolic compounds studied, hydroxytyrosol and oleuropein were those whith higher losses. Such fact could be attributed to their antioxidant capacity, once that ortho-diphenols present higher capacity to protect lipid targets from oxidation (Bester et al., 2008; Carrasco-Pancorbo et al., 2005). These compounds were the first to counterattack the oxidation process suffering higher losses than the remaining phenolic compounds.

\subsubsection{Chlorophylls and carotenoids}

Chlorophylls and carotenoids are the main responsible for the color of olive oils that changes from yellow-green to greenish gold (Criado et al., 2008). Green color is attributed to chlorophylls while the yellow color is mainly related with carotenoids content. These pigments play an important role in the oxidative stability of oils ( $\beta$-caroten and others carotenoid compounds) but chlorophylls play a dualistic role, behaving as antioxidants in the dark, but becoming pro-oxidative agent when exposed to light (Sapino et al., 2005). These pigments are absent in most refined vegetable oils, being eliminated during the discoloration step (Albi et al., 1997a). 
Concerning the effect of microwave heating in pigments of several categories of crude oils, the results are conclusive, microwave heating leads to the destruction of large quantities of chlorophylls, flavonoids and carotenoids, as reported in several works (Albi et al., 1997a; Oomah et al., 1998, Khan et al., 2010; Malheiro et al., 2009; El-Abassy et al., 2010). Grapeseed crude oil extracted from microwave dried seeds had reduced pigmentation at $410 \mathrm{~nm}$ and $670 \mathrm{~nm}$, corresponding to total chlorophylls and carotenois, respectively, when compared with conventional drying (Oomah et al., 1998). Albi et al. (1997a) reported a similar behavior for both extra virgin olive oil and olive oil (refined + virgin olive oil) when exposed to microwave energy. No effects on chlorophylls and carotenoids contents were reported when the oils were put in contact with microwave energy without temperature increasing. When heated, higher generalized losses of carotenoids and chlorophyls were observed in the microwave heated samples when compared with conventional heated ones, more noticeable in the carotenoids (Albi et al., 1997a). A decrease in chlorophylls and carotenoids contents was also reported with extra virgins and virgin PDO Portuguese olive oils submitted to increasing microwave exposure (Malheiro et al., 2009), again higher for carotenoids than for chlorophylls: after 15 minutes of microwave heating, chlorophylls content decreased between 33.1 and $52.9 \%$ while carotenoids suffers considerable losses, between 77.3 and $89.3 \%$. The color losses discussed previously can be chemically supported by these observations (see topic 2.1.2).

El-Abassy et al. (2010) reported that carotenoids degradation seems to be related with the exposure time and less with the final temperature reached. The authors monitored carotenoids degradation by VIS Raman spectroscopy and observed that the Raman bands corresponding to carotenoids $\left(1008,1150\right.$, and $\left.1525 \mathrm{~cm}^{-1}\right)$ completely disappeared at $203{ }^{\circ} \mathrm{C}$ in conventional heating, being observed even up to $225^{\circ} \mathrm{C}$ with microwave heating. In this case, microwave oven needed 12 minutes to reach the $225^{\circ} \mathrm{C}$ while in the conventional oven the $203{ }^{\circ} \mathrm{C}$ were reached after 80 minutes of heating.

These results and facts show and corroborate that chlorophyll and carotenoids are thermolabile pigments and that microwave heating induces a decrease in their content, causing higher damages in carotenoids content. Whether these observations are more dependent on the heat exposure time or the temperatures achieved within the process is an interesting issue that deserves more study.

\section{Conclusions}

Microwave heating features modern lifestyle. The use of this technology enables a significant reduction in the time dedicated to prepare meals and opens new perspectives at the industrial level. In this chapter we report the combined effect of time/applied potency of microwave heating in comparison to conventional electric oven on the quality of vegetable oils.

In general, the degradation pattern of vegetable oils under microwave heating was similar to that expected from other conventional heating methods, including oxidation, hydrolysis and polymerization. Nevertheless, microwave heating induced higher degradation extent, as confirmed by the physical and chemical evaluations reported, reducing the nutritional value of lipids. The combination of temperature and energy effects induced by microwaves, which could have strengthened the heating effect might lead to zonal overheating in the oils, 
a situation that deserves technological improvement. Nevertheless, most of the published studies compared high exposure times and temperatures, unusual on microwave domestic procedures, except for microwave frying. Therefore, the vegetable oils behavior under real cooking practices, power settings, and combined interaction of different ingredients, needs to be further exploit in order to provide concise information from nutritional, technological and health points of view. Based on these prospects and scientific findings the use of microwave is not discouraged, but vegetable oils heating should be reduced to the minimum, in order to reduce the degradation extent of important compounds, as lipossoluble vitamins, essential fatty acids, and phenolics, while reducing the formation of potentially hazard components, the oxidized lipids.

\section{References}

Albi, T.; Lanzón, A.; Guinda, A.; Pérez-Camino, M.C. \& León, M. (1997a). Microwave and conventional heating effects on some physical and chemical parameters of edible fats. Journal of Agricultural and Food Chemistry, 45, 3000-3003.

Albi, T.; Lanzón, A.; Guinda, M.; Léon, M. \& Pérez-Camino, M.C. (1997b). Microwave and conventional heating effects on thermoxidative degradation of edible oils. Journal of Agricultural and Food Chemistry, 45, 3795-3798.

Beekrum, S.; Govinden, R.; Padayachee, T. \& Odhav, B. (2003). Naturally occurring phenols: a detoxification strategy for fumonisin B-1. Food Additives $\mathcal{E}$ Contaminants: Part A Chemistry, 20, 490-493.

Ben Othman, N.; Roblain, D.; Chammen, N.; Thonart, P. \& Hamdi, M. (2009). Antioxidant phenolic compounds loss during the fermentation of Chétoui olives. Food Chemistry, 116, 662-669.

Bešter, E.; Butinar, B.; Bučar-Miklavčič, M. \& Golob, T. (2008). Chemical changes in extra virgin olive oil from Slovenian Istra after thermal treatment. Food Chemistry, 108, 446-454.

Brenes, M.; García, A.; Dobarganes, M.C.; Velasco, J. \& Romero, C. (2002). Influence of thermal treatments simulating cooking processes on the polyphenol content in virgin olive oil. Journal of Agricultural and Food Chemistry, 50, 5962-5967.

Cañabate-Díaz, B.; Carratero, A.S.; Fernández-Gutiérrez, A.F.; Vega, A.B.; Frenich, A.G.; Vidal, J.L.M. \& Martos, J.D. (2007). Separation and determination of sterols in olive oil by HPLC-MS. Food Chemistry, 102, 593-598.

Caponio, F.; Pasqualone, A. \& Gomes, T. (2002). Effects of conventional and microwave heating on the degradation of olive oil. European Food Research and Technology, 215, 114-117.

Caponio, F.; Pasqualone, A. \& Gomes, T. (2003). Changes in the fatty acids composition of vegetable oils in model doughs submitted to conventional or microwave heating. International Journal of Food Science and Technology, 38, 481-486.

Carrasco-Pancorbo, A.; Cerretani, L.; Bendini, A.; Segura-Carretero, A.; Del Carlo, M.; Gallina-Toschi, T.; Lercker, G.; Compagnone, D. \& Fernández-Gutiérrez, A. (2005). Evaluation of the antioxidant capacity of individual phenolic compounds in virgin olive oil. Journal of Agricultural and Food Chemistry, 53, 8918-8925. 
Cerretani, L.; Bendini, A.; Rodeiguez-Estrada, M.T.; Vittadini, E. \& Chiavaro, E. (2009). Microwave heating of different commercial categories of olive oil: Part I. Effect on chemical oxidative stability indices and phenolic compounds. Food Chemistry, 115, 1381-1388.

Chavan, R.S. \& Chavan, S.R. (2010). Microwave baking in food industry: a review. International Journal of Dairy Science, 5, 113-127.

Chiavaro, E.; Rodriguez-Estrada, M.T.; Vittadini, E. \& Pellegrini, N. (2010). Microwave heating of different vegetable oils: Relation between chemical and thermal parameters. LWT - Food Science and Tecnology, 43, 1104-1112.

Cossignani, L.; Simonetti, M.S.; Neri, A. \& Damiani, P. (1998). Changes in olive oil composition due to microwave heating. Journal of the American Oil Chemists' Society, 75, 931-937.

Criado, M. -N.; Romero, M. -P.; Casanovas, M. \& Motilva, M.J. (2008). Pigment profile and colour of monovarietal virgin olive oils from Arbequina cultivar obtained during two consecutive crop seasons. Food Chemistry, 110, 873-880.

Dostálová J.; Hanzlík, P.; éblová Z. \& Pokorný J. (2005). Oxidative changes of vegetable oils during microwave heating. Czech Journal of Food Science, 23, 230-239.

El-Abassy, R.M.; Donfack, P. \& Materny, A. (2010). Assessment of conventional and microwave heating induced degradation of carotenoids in olive oil by VIS Raman spectroscopy and classical methods. Food Research International, 43, 694700 .

Eskin, N.A.M.; McDonald, B.E.; Przybylski, R.; Malcolmson, L.J.; Scarth, R.; Mag, T.; Ward, K.; \& Adolph, D. (1996). Canola Oil. In Bailey's Industrial Oil and Fat Products, Vol. 2, Edible Oil and Fat Products: Oil and Oilseeds, 5th ed.; Y.H. Hui (Ed.), 1-95, Wiley, John \& Sons, ISBN 9780471594246, New York, USA.

EEC, European Economic Community (1991). Commission Regulation 2568/91 of 11 July 1991 on the characteristics of olive oil and olive-residue oil and on the relevant methods of analysis. Official Journal of European Communities, L248.

Hassanein, M.M.; El-Shami, S.M. \& El-Mallah, M.H. (2003). Changes occurring in vegetable oils composition due to microwave heating. Grasas y Aceites, 54, 343-349.

Khan, M.N.; Sarwar, A. \& Wahab, M.F. (2010). Chemometric assessment of thermal oxidation of some edible oils. Effect of hot plate heating and microwave heating on physicochemical properties. Journal of Thermal Analysis and Calorimetry, in Press.

Labrinea, E.P.; Thomaidis, N.S.; \& Georgiou, C.A., 2001. Direct olive oil anisidine value determination by flow injection. Analytica Chimica Acta, 448, 201-206.

Laguerre, M.; Lecomte, J. \& Villeneuve, P. (2007). Evaluation of the ability of antioxidants to counteract lipid oxidation: Existing methods, new trends and challenges. Progress in Lipid Research, 46, 244-282.

Li, D. \& Sinclair, A.J. (2002). Macronutrient innovations: The role of fats and sterols in human health. Asia Pacific Journal of Clinical Nutrition, 11, S155-S162.

Mahmoud, E.A.E-M.; Dostálová, J.; Pokornỹ, J.; Lukešová, D. \& Doležal, M. (2009). Oxidation of olive oils during microwave and conventional heating for fast food preparation. Czech Journal of Food Sciences, 27, S173-S177. 
Malheiro, R.; Oliveira, I.; Vilas-Boas, M.; Falcão, S.; Bento, A. \& Pereira, J.A. (2009). Effect of microwave heating with different exposure times on physical and chemical parameters of olive oil. Food and Chemical Toxicology, 47, 92-97.

Marsilio, V.; Campestre, C. \& Lanza, B. (2001). Phenolic compounds change during California-style ripe olive processing. Food Chemistry, 74, 55-60.

Mutyala, S.; Fairbridge, C.; Pare, J.R.J.; Bélanger, J.M.R.; Ng, S. \& Hawkins R. (2010). Microwave applications to oil sands and petroleum: A review. Fuel Processing Technology, 91, 127-135.

Oomah, B.D.; Liang, J.; Godfrey, D. \& Mazza, G. (1998). Microwave heating of grapeseed: effect on oil quality. Journal of Agricultural and Food Chemistry, 46, 4017-4021.

Osepchuk, J.M. (1984). A history of Microwave heating application. IEEE Transactions on Microwave theory and Techniques, MTT-32, 9, 1200-1224.

Portaria No. 1135/95, 1995. Diário da República. I Série-B, No. 214, p. 5836.

Sapino, S.; Carlotti, M.E.; Peira, E. \& Gallarate, M. (2005). Hemp-seed and olive oils: their stability against oxidation and use in $\mathrm{O} / \mathrm{W}$ emulsions. Journal of Cosmetic Science, 56, 227-251.

Sahin S. \& Sumnu S.G (2009). Alternative Frying Technologies, In: Advances in Deep-Fat Frying of Food, Serpil Sahin and Servet Gülüm Sumnu (Ed.), 289-302, CRC Press, ISBN 9781420055580, Boca Raton.

Schouw, Y.T.; Kleijn, M.J.J.; Peeters, P.H.M. \& Grobbee, D.E. (2000). Phytoestrogens and cardiovascular disease risk. Nutrition, Metabolism and Cardiovascular Diseases, 10, 154-167.

Servilli, M. \& Montedoro, G. (2002). Contribution of phenolic compounds to virgin olive oil quality. European Journal of Lipid Science and Technology, 104, 602-613.

Sousa, A.; Ferreira, I.C.F.R.; Calhelha, R.; Andrade, P.B.; Valentão, P.; Seabra, R.; Estevinho, L.; Bento, A. \& Pereira, J.A. (2006). Phenolics and antimicrobial activity of traditional stoned table olives "alcaparra". Bioorganic \& Medicinal Chemistry, 14, 8533-8538.

Tan, C.P.; Che Man, Y.B.; Jinap, S. \& Yusoff, M.S.A. (2001). Effects of microwave heating on changes in chemical and thermal properties of vegetable oils. Journal of the American Oil Chemist's Society, 78, 1227-1232.

Tuck, K.L. \& Hayball, P.J. (2002). Major phenolic compounds in olive oil: metabolism and health effects. Journal of Nutritional Biochemistry, 13, 636-644.

Vieira, T.M.F.S. \& Regitano-d'Arce, M.A.B. (1999). Ultraviolet spectrophotometric evaluation of corn oil oxidative stability during microwave heating and oven test. Journal of Agricultural and Food Chemistry, 47, 2203-2206.

Yoshida, H.; Hirooka, N. \& Kajimoto, G. (1991a). Microwave heating effects on relative stabilities of tocopherols in oils. Journal of Food Science, 56, 1042-1046.

Yoshida, H.; Shigezaki, J.; Takagi, S. \& Kajimoto, G. (1995). Variations in the composition of various acyl lipids, tocopherols and lignans in sesame seed oils roasted in a microwave oven. Journal of the Science of Food and Agriculture, 68, 407-415.

Yoshida, H.; Tatsumi, M. \& Kajimoto, G. (1991b). Relationship between oxidative stability of vitamin $\mathrm{E}$ and production of fatty acids in oils during microwave heating. Journal of the American Oil Chemists' Society, 68, 566-570. 
Yoshida, H.; Tatsumi, M. \& Kajimoto, G. (1992). Influence of fatty acids on the tocopherol stability in vegetable oils during microwave heating. Journal of the American Oil Chemists' Society, 69, 119-125. 


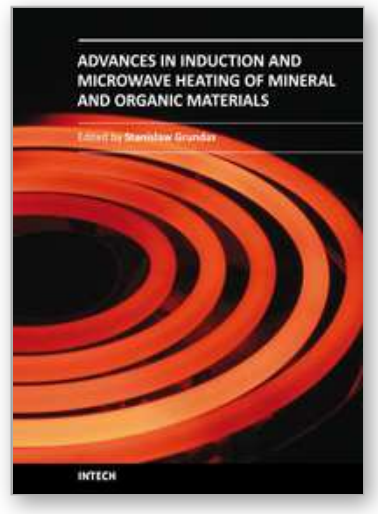

\section{Advances in Induction and Microwave Heating of Mineral and Organic Materials}

Edited by Prof. StanisÅ,aw Grundas

ISBN 978-953-307-522-8

Hard cover, 752 pages

Publisher InTech

Published online 14, February, 2011

Published in print edition February, 2011

The book offers comprehensive coverage of the broad range of scientific knowledge in the fields of advances in induction and microwave heating of mineral and organic materials. Beginning with industry application in many areas of practical application to mineral materials and ending with raw materials of agriculture origin the authors, specialists in different scientific area, present their results in the two sections: Section 1-Induction and Microwave Heating of Mineral Materials, and Section 2-Microwave Heating of Organic Materials.

\section{How to reference}

In order to correctly reference this scholarly work, feel free to copy and paste the following:

Ricardo Malheiro, Susana Casal, Elsa Ramalhosa and José Alberto Pereira (2011). Microwave Heating: A Time Saving Technology or a Way to Induce Vegetable Oils Oxidation?, Advances in Induction and Microwave Heating of Mineral and Organic Materials, Prof. StanisÅ,aw Grundas (Ed.), ISBN: 978-953-307-522-8, InTech, Available from: http://www.intechopen.com/books/advances-in-induction-and-microwave-heating-of-mineraland-organic-materials/microwave-heating-a-time-saving-technology-or-a-way-to-induce-vegetable-oilsoxidation-

\section{INTECH}

open science | open minds

\section{InTech Europe}

University Campus STeP Ri

Slavka Krautzeka 83/A

51000 Rijeka, Croatia

Phone: +385 (51) 770447

Fax: +385 (51) 686166

www.intechopen.com

\section{InTech China}

Unit 405, Office Block, Hotel Equatorial Shanghai

No.65, Yan An Road (West), Shanghai, 200040, China

中国上海市延安西路65号上海国际贵都大饭店办公楼405单元

Phone: +86-21-62489820

Fax: $+86-21-62489821$ 
(C) 2011 The Author(s). Licensee IntechOpen. This chapter is distributed under the terms of the Creative Commons Attribution-NonCommercialShareAlike-3.0 License, which permits use, distribution and reproduction for non-commercial purposes, provided the original is properly cited and derivative works building on this content are distributed under the same license. 